\title{
Source Complexity of the 1994 Northridge Earthquake and Its Relation
}

\section{to Aftershock Mechanisms}

\author{
by Hong Kie Thio* and Hiroo Kanamori
}

\begin{abstract}
We determined the source process of the 1994 Northridge earthquake in relation to the aftershock mechanisms. To study the source complexity of the mainshock, we inverted the $P$ and $S H$ waveforms recorded by the IRIS and IDA/IRIS networks, using the method of Kikuchi and Kanamori (1991) in which the rupture is represented by a series of discrete subevents with varying mechanisms. The waveforms show that the rupture consisted of several subevents with about $2 \mathrm{sec}$ in between. Our solution consists of three subevents with essentially the same mechanism, viz., strike, dip, and slip of $130^{\circ}, 42^{\circ}$, and $116^{\circ}$, respectively. The first subevent occurred at a depth of about $19 \mathrm{~km}$, followed after $2 \mathrm{sec}$ by the second and largest subevent at a depth of $17 \mathrm{~km}$ and the third subevent again $2 \mathrm{sec}$ after the second at a depth of about $13 \mathrm{~km}$. The total moment from the body waves of this sequence is about $1.1 \times 10^{26} \mathrm{dyne} \cdot \mathrm{cm}\left(M_{W}=6.6\right)$ with a source duration of $7 \mathrm{sec}$.

The large depths of these subevents explain the lack of any surface rupture. Furthermore, the upward propagation of the subevents is consistent with the depth of the hypocenter and the distribution of the aftershocks, which are shallower and more northerly than the mainshock hypocenter.

The aftershocks were analyzed using data from the TERRAscope network. We inverted short-period surface waves to determine the moment tensor for 70 events with $M_{W}>3.5$. The aftershocks can be grouped into three regions based on the mechanisms: the eastern part of the aftershock zone, where we find thrust events with mechanisms very similar to the main event; a central area with predominantly strike-slip events; and an area to the west, where we find oblique thrust events but with more northerly $P$ axes than in the eastern region. This distribution suggests that the fault system on which the Northridge earthquake occurred is segmented and that the extent of the Northridge rupture is controlled by a change in geometry of the fault. We find a high stress drop (270 bar) for the mainshock; we propose that the changes in the fault geometry prevented a slip pulse from propagating, thereby causing a high ratio of slip-to-rupture length.
\end{abstract}

\section{Introduction}

The Northridge earthquake $\left(M_{W}=6.7\right)$ is the largest earthquake to have occurred in the Los Angeles metropolitan area in this century. The epicenter (latitude $34.21^{\circ} \mathrm{N}$, longitude $118.55^{\circ} \mathrm{W}$ ) was located in the San Fernando Valley, southwest of the 1971 San Fernando earthquake (Fig. 1). Due to its location, the earthquake caused a considerable amount of casualties and damage in the Santa Clarita Valley, the San Fernando Valley, and the northern Los Angeles Ba$\sin$ (Scientists of the USGS and SCEC, 1994). The aftershocks span an area of about $20 \times 30 \mathrm{~km}^{2}$ (Hauksson et al.,

* Present address: Woodward-Clyde Federal Services, 566 El Dorado Street, Pasadena, California 91101.
1995), with the largest concentration in the northeast of the mainshock hypocenter. In cross section, the mainshock location and the aftershock distribution suggest that the rupture propagated upward on a south-dipping fault plane. The mechanism, a thrust, is similar to that of the San Fernando earthquake, but the actual rupture plane is south dipping in contrast to the north-dipping fault plane of the San Fernando earthquake (Whitcomb et al., 1973).

The fault on which the Northridge earthquake occurred is part of a larger system of faults in the Transverse Ranges. The fault system in the Transverse Ranges is under NNW compression (Norris and Webb, 1990). This compressive stress environment is associated with the big bend of the San 


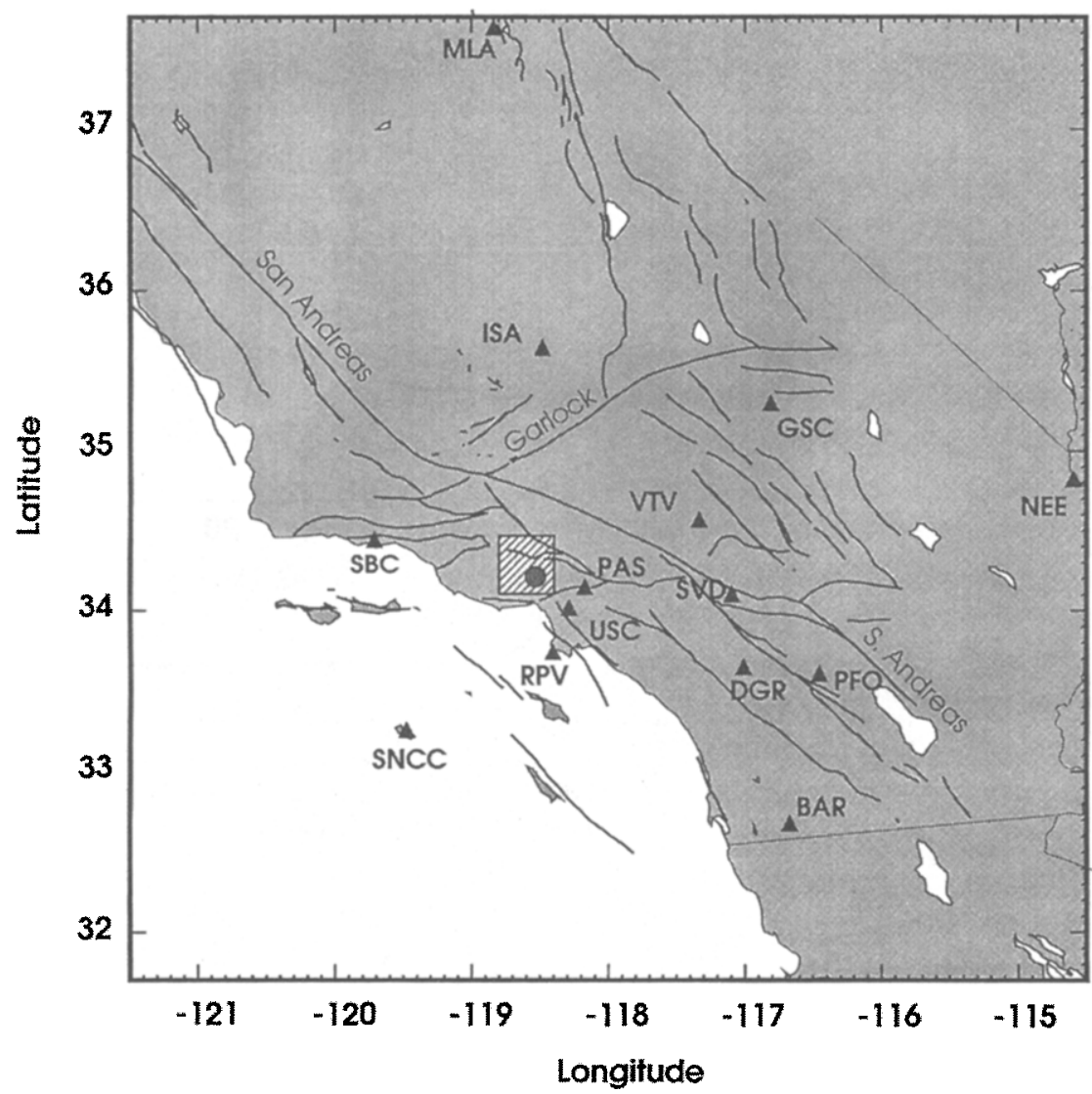

- Stations

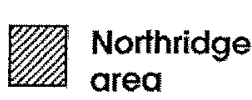

- Epicenter

Figure 1. Map of southern California, with the major faults and the distribution of the TERRAscope network. The shaded area is the epicentral area of the 1994 Northridge earthquake. The gray circle is the epicenter.

Andreas fault, the main boundary between the North American and Pacific plates (Fig. 1).

Since 1971, there have been numerous earthquakes along the Transverse Ranges, notably the 1971 San Fernando earthquake $\left(M_{W}=6.6\right)$ but more recently the 1990 Upland earthquake $\left(M_{W}=5.5\right.$, Dreger and Helmberger, 1991a), the 1991 Sierra Madre $\left(M_{W}=5.8\right.$, Dreger and Helmberger, 1991b), and the 1989 Pasadena $\left(M_{L}=4.9\right.$, Kanamori et al., 1990) earthquakes. The San Fernando earthquake occurred just northeast of the Northridge earthquake, with some overlap of the two aftershock zones (Mori et al., 1994). Rupture during the San Fernando earthquake reached the surface and produced surface breaks at several locations. The aftershock distribution shows a distinct pattern with the western edge of the aftershock zone having a sharp linear distribution of aftershocks in the NE-SW direction. In this area, the mechanisms are predominantly strike slip with the strike aligned to the orientation of the edge. This arrangement led Whitcomb et al. (1973) to the conclusion that the fault plane is offset along a western lineament and that this offset may have limited the extent of the San Fernando rupture.

In this article, we determined the spatial extent and the complexity of the mainshock rupture using teleseismic body waves and the mechanisms of the larger aftershocks using TERRAscope data. We will show that there is a connection between the aftershock mechanisms and the mainshock rupture area and will suggest that the extent of the rupture is influenced by complexities of the fault plane, which are reflected in the aftershock mechanisms.

\section{Data and Methods}

In the first part of this study, we used body-wave ( $P$ and $S H$ ) data, from the IRIS and IDA/IRIS networks (Fig. 2), with epicentral distances between $30^{\circ}$ and $90^{\circ}$. All the data were deconvolved to displacement through a very wide passband $(0.0033$ to $4 \mathrm{~Hz})$. The waveform is relatively simple. The simplicity of teleseismic waveforms is often characteristic of dip-slip earthquakes, for which $P$ waves to teleseismic stations leave the source in the direction close to the radiation maximum, resulting in clean waveforms (Fig. 3). However, Figure 3 shows some evidence for source complexity. We can distinguish at least three episodes of energy release in the $P$ waves approximately $2 \mathrm{sec}$ apart, the second episode being the largest. In order to determine the spatial and tem- 


\section{Station distribution}

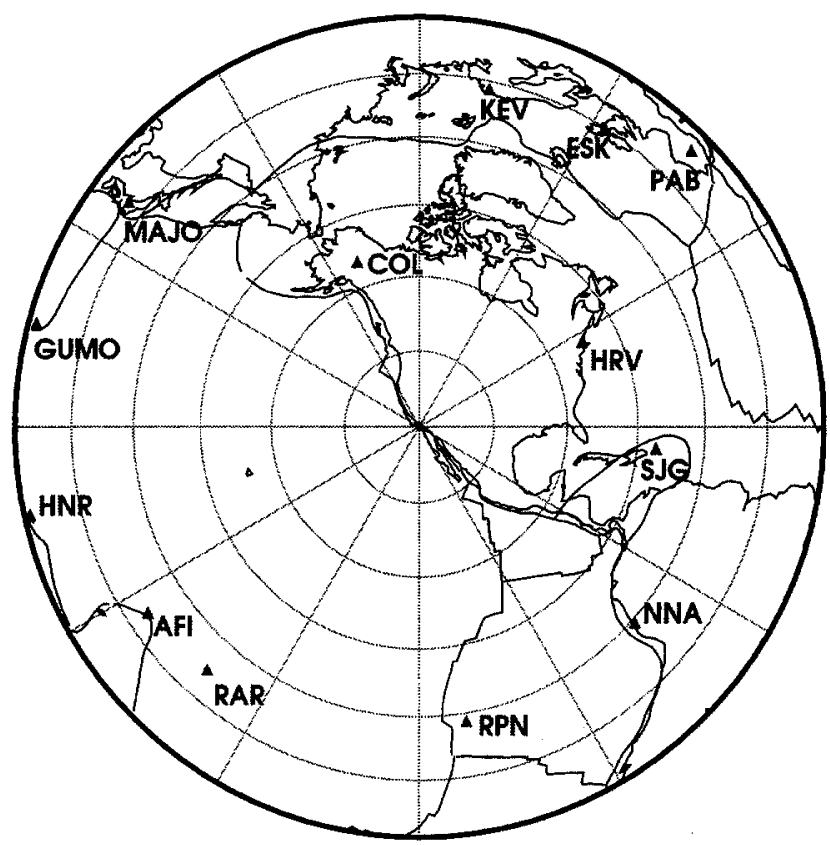

Figure 2. Station distribution for the teleseismic waveform inversion. This distribution is an azimuthal projection centered on Northridge, with a maximum distance of $90^{\circ}$.

poral distribution of the energy release, we used the method of Kikuchi and Kanamori (1991), where the $P$ and $S H$ waveforms are inverted to determine the subevent distribution, allowing the mechanisms of the individual subevents to vary. This procedure is accomplished by computing synthetic wave forms from the fundamental Green's functions at all stations and choosing the mechanism (including location and timing) with the largest correlation coefficient.

In the second part of our study, we determined the source mechanisms of the aftershocks using the data from the TERRAscope network. We determined the complex spectrum of the fundamental mode surface waves, usually over a period range of 10 to $40 \mathrm{sec}$, on the vertical and tangential components (Thio and Kanamori, 1995a); applied propagation corrections to the spectrum; and determined the source spectrum. This source spectrum is inverted for the moment-tensor elements. We determined the depth of these events by performing inversions for different depths and choosing the depth that gives the best fit.

\section{Mainshock Inversion}

We computed Green's functions using a layered model of southern California obtained by Magistrale et al. (1991). It consists of a slow sedimentary layer on top of the crustal model that is widely used in seismic studies in southern California (Table 1).

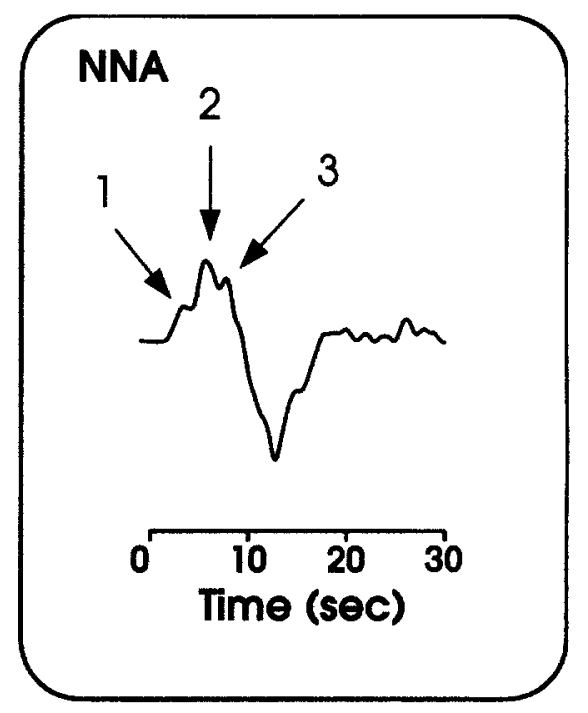

Figure 3. $P$ wave recorded at station NNA in Chile. The data have been deconvolved to displacement. Note the individual pulses (numbered) that indicate nonuniform energy release.

Table 1

Velocity Structure Used in the Body-Wave Inversion

\begin{tabular}{cccc}
\hline Thickness & $\begin{array}{c}P \\
(\mathrm{~km} / \mathrm{sec})\end{array}$ & $\begin{array}{c}S \\
(\mathrm{~km} / \mathrm{sec})\end{array}$ & $\begin{array}{c}\rho \\
\left(\mathrm{g} / \mathrm{cm}^{3}\right)\end{array}$ \\
\hline 0.5 & 2.4 & 1.4 & 2.0 \\
1.0 & 3.8 & 2.2 & 2.1 \\
4.0 & 5.2 & 3.0 & 2.4 \\
9.5 & 6.2 & 3.6 & 2.7 \\
19.0 & 6.6 & 3.8 & 2.8 \\
\hline
\end{tabular}

To determine the overall mechanism, we first inverted the seismograms using a long $(8 \mathrm{sec})$ time function and only one subevent. This step yielded an event with a strike of about $130^{\circ}$, dip of $40^{\circ}$, rake of $115^{\circ}$, and a depth of $17 \mathrm{~km}$. On the basis of these results as well as information on the main- and aftershock locations, provided by the Southern California Seismic Network (SCSN), we set up a grid network on a plane with a dip of $45^{\circ}$ and a strike of $130^{\circ}$. The grid points are distributed at depths between 10 and $20 \mathrm{~km}$.

We subsequently carried out the inversion with a series of subevents (up to 4) with individual time functions ranging in width from 2 to $4 \mathrm{sec}$. Using two subevents could not explain all the details in the $P$ waveforms, whereas four subevents resulted in an unstable solution. The best result was obtained with three subevents (Fig. 4, Table 2). The mechanisms of the subevent were not fixed or constrained but determined by the inversion. Thus, the similarity of the subevents means that the mechanism did not change during rupture. In fact, the differences between the first and second are insignificant. The depths of the subevents can be well resolved with depth phases ( $p P$ and $s P$ ). They indicate that the rupture propagated updip, starting at a depth of about $19 \mathrm{~km}$ 


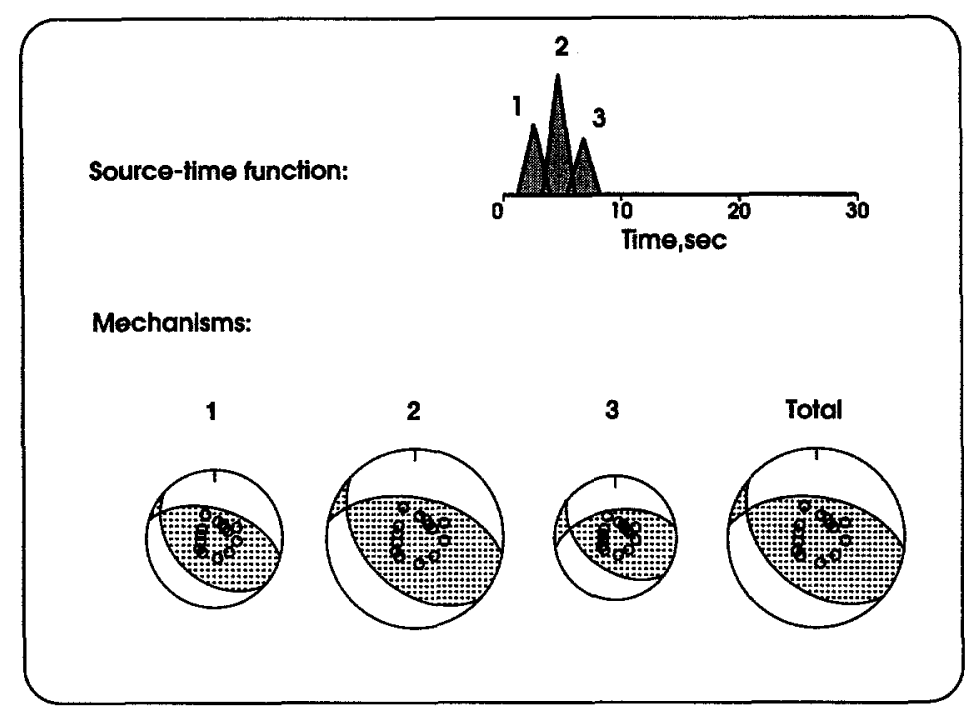

Figure 4. Source time functions and mechanisms of the three subevents. The best results were obtained using three subevents. Note that the first two subevents are essentially similar.
Table 2

Source Parameters for the Subevents Obtained in the First Inversion Procedure

\begin{tabular}{cllllllc}
\hline Subevent & Time & $\Delta x^{*}$ & Depth & Strike & Dip & Slip & $\begin{array}{c}\text { Moment } \\
\times 10^{25} \text { dyne.cm }\end{array}$ \\
\hline 1 & 0 & 0 & 19. & 132. & 39. & 111. & 2.98 \\
2 & 2.1 & 2.5 & 17.5 & 133. & 42. & 115. & 5.04 \\
3 & 4.2 & 2.5 & 14.0 & 127. & 47. & 125. & 2.40 \\
\hline
\end{tabular}

*Measured along Strike $\left(310^{\circ}\right)$ from the hypocenter.

with the largest energy release starting at $17 \mathrm{~km}$ and the last subevent at $14 \mathrm{~km}$. The centroid depth of the Northridge rupture as a whole is around 15 to $16 \mathrm{~km}$. Our inversion suggests that the width (in the horizontal direction) of the rupture zone is narrow, on the order of $3 \mathrm{~km}$, but the horizontal resolution of the location of the subevents in our inversion method is limited to approximately $10 \mathrm{~km}$. Hence, this limitation means that the horizontal extent of the rupture did not exceed $10 \mathrm{~km}$, which is consistent with the aftershock distribution of the first $11 \mathrm{hr}$.

The above results were obtained using simple triangular time functions. To explore the degree of complexity of the rupture, we carried out a second inversion where we fixed the mechanism and location of each of the three subevents but allowed the time function to have a more complex shape than a single triangle. This inversion was done by representing each subevent with several narrow triangular time functions (Kikuchi and Kanamori, 1991). To evaluate the significance of the mechanism change, we inverted the data for two cases: one with a different mechanism for each subevent and the other with the same mechanism for all subevents. The results of the inversion with variable mechanisms and with a single mechanism were only marginally different, and we conclude that no significant change of mechanism occurred during the rupture. Therefore, we used a single mechanism in the subsequent analysis.
The resulting time function is plotted in Figure 5. This time function is of course smoother than that shown in Figure 4 , but the three pulses remain distinct. The seismic moment obtained by the second inversion is $1.1 \times 10^{26}$ dyne $\cdot \mathrm{cm}$, which is slightly smaller than the moment derived from long-period ( 300 to $150 \mathrm{sec}$ ) surface waves, viz., $1.5 \times 10^{26}$ dyne $\cdot \mathrm{cm}$, or regional short-period surface waves, $1.6 \times 10^{26}$ dyne $\cdot \mathrm{cm}$ (see below) but similar to results by Dreger $\left(1994 ; M_{0}=1.2 \times 10^{26} \mathrm{dyne} \cdot \mathrm{cm}\right)$ and Wald and Heaton (1994; $M_{0}=1.2 \times 10^{26}$ dyne $\cdot \mathrm{cm}$ ), which are based on local and regional body waves.

Looking at our rupture model in cross section (Fig. 6), we see that the aftershock density along the fault plane becomes much higher above our rupture zone. This phenomenon is frequently observed in aftershock sequences and suggests that tectonic stresses are relieved on the actual rupture plane but increase outside the ruptured areas (Mendoza and Hartzell, 1988). If we assume that the rupture extended 10 $\mathrm{km}$ in the updip direction as well as laterally, then we can estimate the slip on the fault plane using $M_{0}=\mu S D$, where $\mu$ (rigidity) $=3.5 \times 10^{11} \mathrm{dyne} / \mathrm{cm}^{2}, S$ (fault surface) $=100$ $\mathrm{km}^{2}$, and $D$ is the displacement. The average slip is then 3 $\mathrm{m}$, a measurement which is large for an earthquake of this size; this large measurement indicates a relatively high stress drop. If we calculate the stress drop using a circular crack model, we obtain an estimate of $270 \mathrm{bar}$. This calculation is similar to the stress drops observed on other earthquakes along the Transverse Ranges (Kanamori, et al., 1993) like the Sierra Madre (460 bar, Dreger and Helmberger, 1991b), Whittier Narrows (750 bar, Bent and Helmberger, 1989), Upland (265 bar, Dreger, 1991a), and Pasadena (200 bar, Kanamori et al., 1990) earthquakes.

\section{Aftershocks}

The Northridge earthquake occurred in the middle of the TERRAscope network so that we have an abundance of 
a)

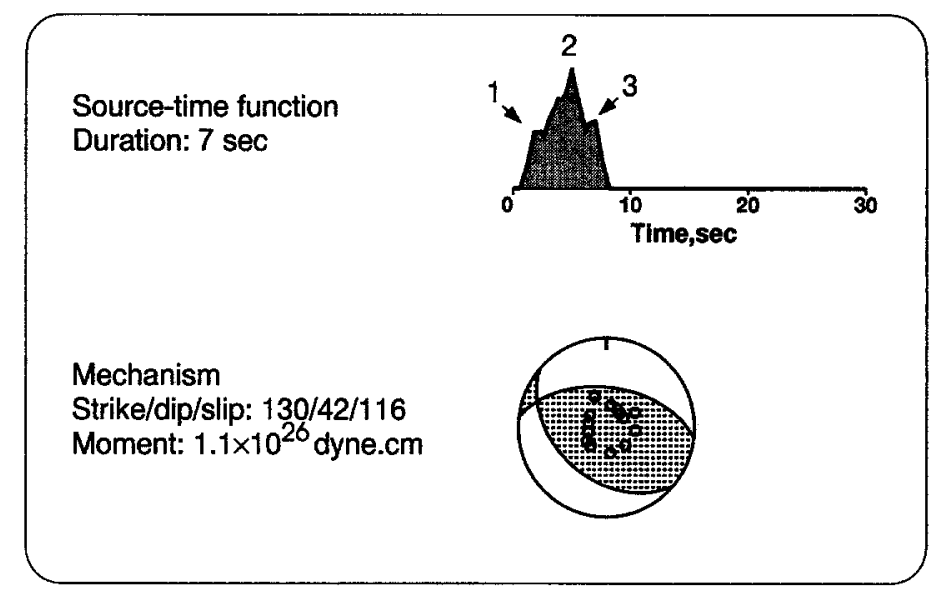

b)

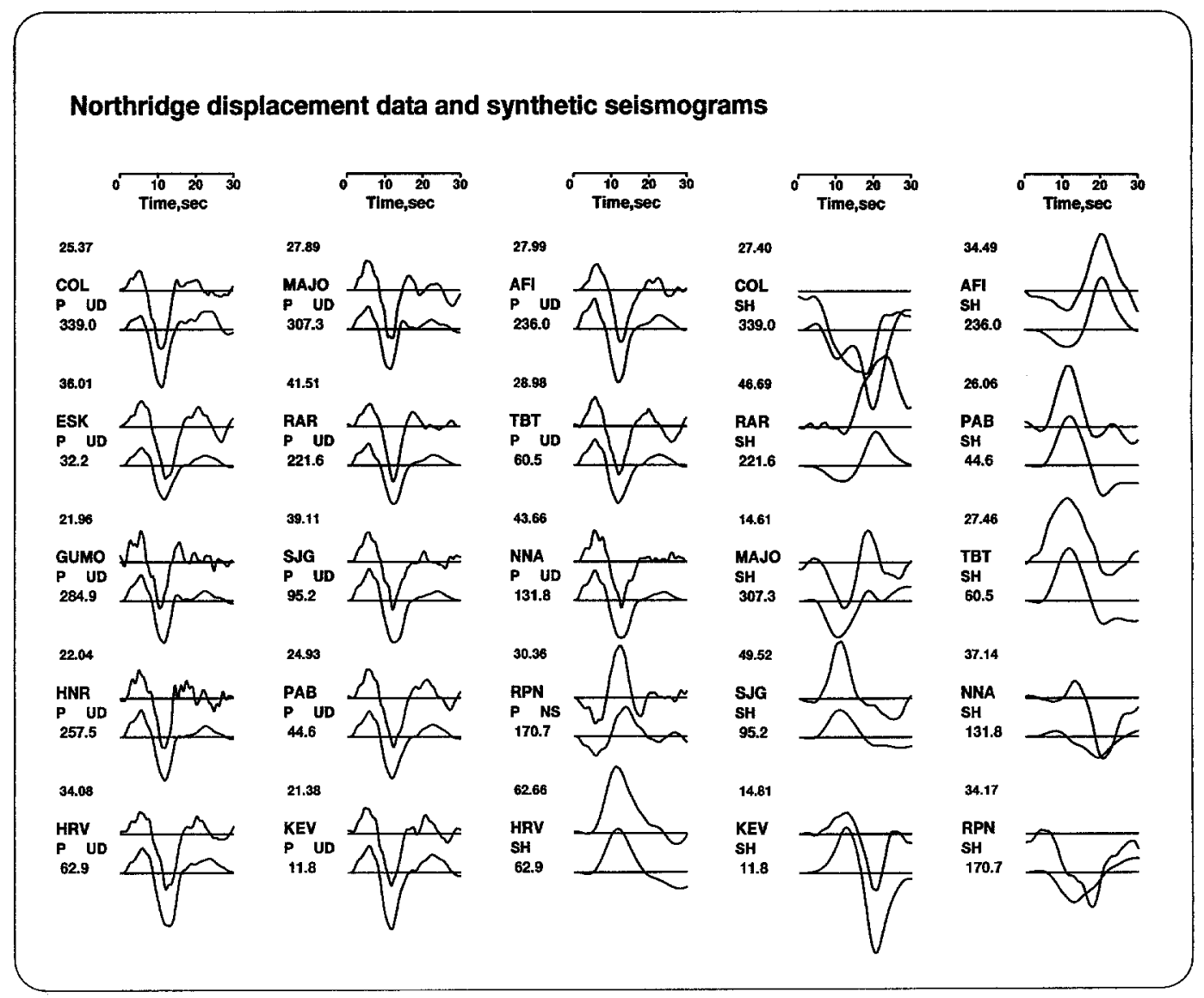

Figure 5. Results from the second inversion. (a) Final source time function and the mechanism used in this inversion. (b) A comparison of data and synthetic seismograms for this solution. The top number at every station is the maximum amplitude for that pair of seismograms; the bottom number is the azimuth from the earthquake. $P$ and $S H$ indicate the type of wave.

high-quality, very broadband data. This location enabled us to make a systematic study of the source mechanisms of the aftershocks using short-period surface waves. The method of Thio and Kanamori (1995a) is used for this analysis. We present solutions for most aftershocks with $M_{W}>3.5$ with the exception of events that followed within the first couple of hours after the mainshock, including the largest after- shock that occurred a few minutes after the main event. The records for these events could not be used because of interference with the mainshock.

Since the source dimension of the mainshock is relatively large compared to the epicentral distances to the TERRAscope stations, the point-source approximation made in our method may not be justified. However, by using some 


\section{Cross section of the Northridge rupture}

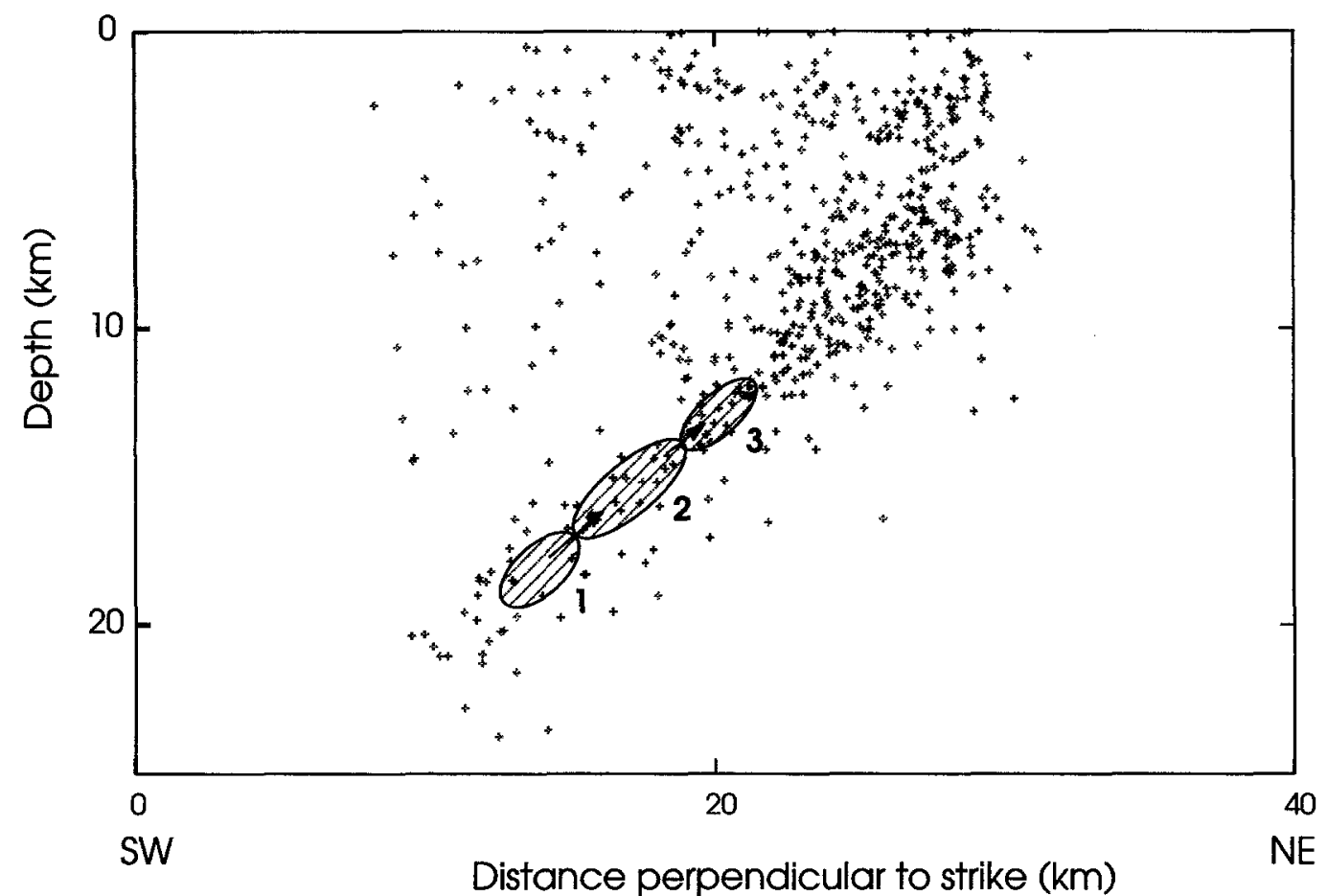

Figure 6. Cross section perpendicular to the strike of the fault plane. The ellipses correspond to the subevents from the teleseismic inversion. The pluses are aftershock locations provided by the Southern California Seismic Network.

of the more distant stations, we were able to determine the mechanism with sufficient accuracy (Fig. 7). The moment of $1.6 \times 10^{26}$ dyne $\cdot \mathrm{cm}$ is larger than that from the body waves, but this may be due to the longer periods involved or to errors arising from the use of the point-source approximation or from the fact that we only used three stations for this inversion. The best results were obtained with a halfduration of $5 \mathrm{sec}$, which is comparable with the body-wave results. The depth, however, was $11 \mathrm{~km}$, which is substantially shallower than the depth found from the SCSN and our body-wave solution. We think that this is also caused by our point-source approximation.

Our inversion method is more suitable for the analysis of smaller events, and the results for the aftershocks are much more reliable than that for the mainshock. The results are given in Table 3 and plotted in Figures 8a through 8c. The mechanisms of the aftershocks are predominantly thrust (Fig. 8a), similar to the mainshock mechanism. There are, however, some larger strike-slip aftershocks (Fig. 8b); in general, the strike-slip mechanisms seem to be concentrated near the center of the aftershock area. East of this zone we find thrust mechanisms similar to the mainshock, whereas to the west (Fig. 8c), we find thrust mechanisms that are more oblique than in the eastern zone with more northerly oriented $P$ axes.

We also compared the $M_{W} / M_{L}$ ratios for the aftershock sequence to see whether there is any trend with respect to

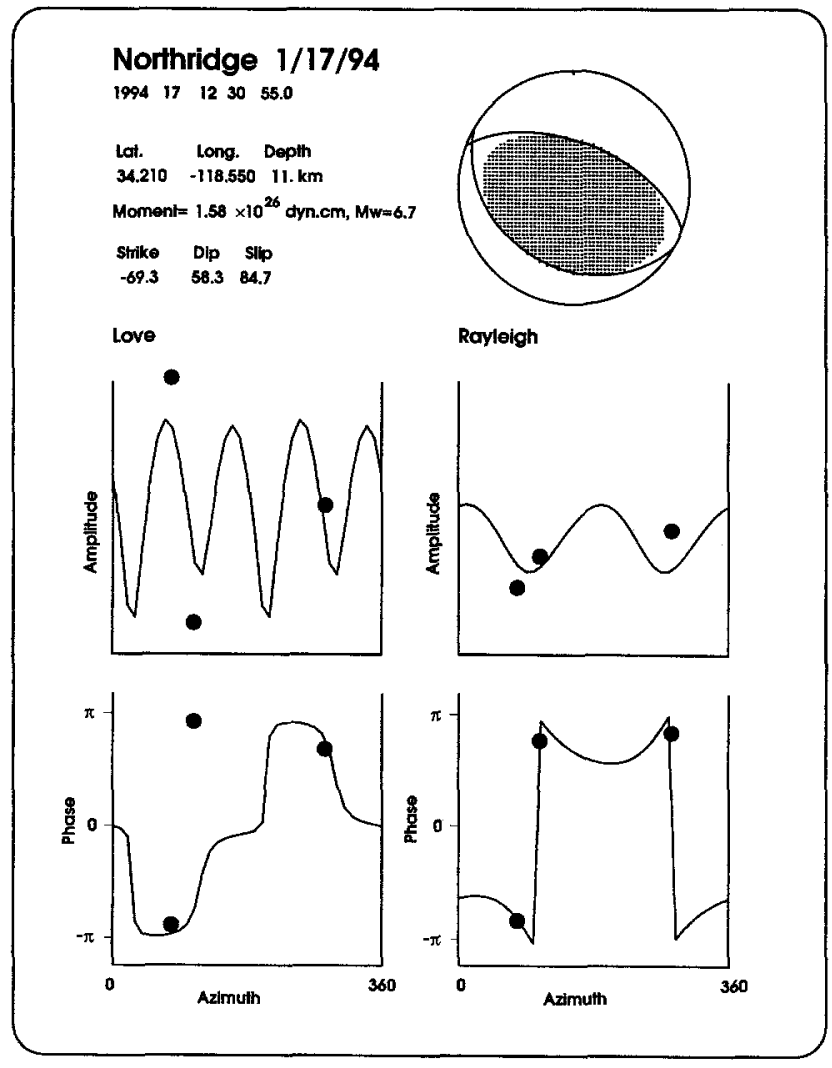

Figure 7. Moment tensor solution for the Northridge earthquake. Three TERRAscope stations were used: SBC, NEE, and PFO. 
Table 3

Mechanisms from the Short-Period Surface-Wave Inversions

\begin{tabular}{|c|c|c|c|c|c|c|c|c|c|c|c|}
\hline \multirow{2}{*}{$\begin{array}{c}\text { Date } \\
(\mathrm{m} / \mathrm{d} / \mathrm{yr})\end{array}$} & \multirow[b]{2}{*}{ Time } & \multicolumn{2}{|c|}{ Moment } & \multirow[b]{2}{*}{$M_{W}$} & \multirow[b]{2}{*}{$M_{L}$} & \multirow[b]{2}{*}{ Strike } & \multirow[b]{2}{*}{ Dip } & \multirow[b]{2}{*}{ Slip } & \multirow[b]{2}{*}{ Lat. } & \multirow[b]{2}{*}{ Long. } & \multirow[b]{2}{*}{ Depth } \\
\hline & & $M_{0}$ & Exp. & & & & & & & & \\
\hline $01 / 17 / 94$ & $12: 30: 55.0$ & 1.6 & 26 & 6.7 & 6.45 & -69 & 58. & 85. & 34.21 & -118.55 & 11. \\
\hline $01 / 17 / 94$ & $17: 56: 08.0$ & 7.0 & 22 & 4.5 & 4.51 & -73 & 58. & 76. & 34.23 & -118.57 & 17. \\
\hline $01 / 17 / 94$ & $18: 20: 24.0$ & 1.6 & 21 & 3.4 & 3.45 & -67 & 46. & 77. & 34.28 & -118.46 & 9. \\
\hline $01 / 17 / 94$ & $18: 32: 09.0$ & 5.0 & 21 & 3.7 & 3.70 & -59 & 30. & 88. & 34.29 & -118.51 & 21. \\
\hline $01 / 17 / 94$ & $19: 23: 54.0$ & 2.1 & 21 & 3.5 & 3.6 & -63 & 24. & 127. & 34.28 & -118.58 & 17. \\
\hline $01 / 17 / 94$ & $19: 43: 53.0$ & 2.5 & 22 & 4.2 & 3.94 & -43 & 30. & 139. & 34.38 & -118.64 & 17 \\
\hline $01 / 17 / 94$ & $19: 58: 48.0$ & 4.8 & 21 & 3.7 & 3.56 & -59 & 9. & 146. & 34.47 & -118.63 & 1. \\
\hline $01 / 17 / 94$ & $20: 02: 05.0$ & 4.9 & 21 & 3.7 & 3.80 & -48 & 22. & 107. & 34.40 & -118.52 & 9. \\
\hline $01 / 17 / 94$ & $20: 05: 28.0$ & 5.6 & 21 & 3.8 & 3.71 & -131 & 51. & -20 & 34.35 & -118.49 & 5. \\
\hline $01 / 17 / 94$ & $20: 11: 49.0$ & 1.9 & 21 & 3.4 & 3.61 & 153. & 68. & 101 & 34.32 & -118.52 & 10. \\
\hline $01 / 17 / 94$ & $20: 17: 38.0$ & 1.5 & 21 & 3.4 & 3.43 & -170 & 44. & -50 & 34.33 & -118.52 & 5 \\
\hline $01 / 17 / 94$ & $20: 38: 25.0$ & 4.8 & 21 & 3.7 & 3.66 & -87 & 85. & 68. & 34.31 & -118.46 & 20. \\
\hline $01 / 17 / 94$ & $20: 46: 03.0$ & 3.5 & 23 & 5.0 & 4.94 & -116 & 88. & 5. & 34.32 & -118.56 & 11. \\
\hline $01 / 17 / 94$ & $22: 07: 43.0$ & 1.7 & 21 & 3.4 & 3.50 & 139. & 48. & -150 & 34.35 & -118.47 & 5. \\
\hline $01 / 17 / 94$ & $22: 19: 24.0$ & 8.1 & 21 & 3.9 & 3.81 & 65. & 61. & 357 & 34.35 & -118.64 & 15. \\
\hline $01 / 17 / 94$ & $23: 33: 31.0$ & 8.2 & 24 & 5.9 & 5.27 & -30 & 40. & 148. & 34.33 & -118.69 & 3. \\
\hline $01 / 18 / 94$ & $00: 39: 35.0$ & 4.0 & 22 & 4.3 & & -74 & 28. & 82. & 34.38 & -118.56 & 13. \\
\hline $01 / 18 / 94$ & $00: 43: 09.0$ & 4.0 & 23 & 5.0 & 5.2 & -56 & 54. & 145. & 34.38 & -118.70 & 12 \\
\hline $01 / 18 / 94$ & $04: 01: 27.0$ & 6.0 & 22 & 4.4 & 4.19 & 90. & 58. & 33. & 34.34 & -118.63 & 1. \\
\hline $01 / 18 / 94$ & $04: 31: 20.0$ & 5.7 & 21 & 3.8 & 3.66 & -138 & 53. & 46. & 34.35 & -118.44 & 14. \\
\hline $01 / 18 / 94$ & $06: 29: 02.0$ & 3.1 & 21 & 3.6 & 3.68 & -84 & 61. & 69 & 34.30 & -118.44 & 14. \\
\hline $01 / 18 / 94$ & $09: 41: 48.0$ & 3.5 & 21 & 3.6 & 3.7 & -37 & 59. & 129. & 34.22 & -118.52 & 16. \\
\hline $01 / 18 / 94$ & $11: 35: 10.0$ & 1.5 & 22 & 4.1 & 4.2 & -116 & 89. & 2. & 34.22 & -118.60 & 4. \\
\hline $01 / 18 / 94$ & $13: 24: 44.0$ & 2.6 & 22 & 4.2 & 4.33 & -107 & 60. & 2. & 34.28 & -118.57 & 4. \\
\hline $01 / 18 / 94$ & $15: 19: 54.0$ & 9.4 & 21 & 3.9 & 3.81 & 73. & 82. & 314. & 34.21 & -118.59 & 5. \\
\hline $01 / 18 / 94$ & $15: 23: 47.0$ & 1.7 & 23 & 4.8 & 4.69 & -95 & 49. & 43. & 34.302 & -118.59 & 9. \\
\hline $01 / 18 / 94$ & $16: 23: 35.0$ & 5.7 & 21 & 3.8 & 3.79 & 67. & 88. & 324. & 34.361 & -118.56 & 5. \\
\hline $01 / 19 / 94$ & $04: 40: 48.0$ & 2.6 & 22 & 4.2 & 4.23 & 176. & 78. & 136. & 34.37 & -118.55 & 1. \\
\hline $01 / 19 / 94$ & $14: 09: 15.0$ & 4.8 & 22 & 4.4 & 4.38 & -68 & 21. & 106. & 34.23 & -118.50 & 11. \\
\hline $01 / 19 / 94$ & $14: 46: 35.0$ & 4.5 & 21 & 3.7 & 4.0 & -56 & 49. & 93. & 34.30 & -118.48 & 11. \\
\hline $01 / 19 / 94$ & $21: 09: 28.0$ & 8.5 & 23 & 5.2 & 4.97 & -76 & 34. & 97. & 34.37 & -118.70 & 13. \\
\hline $01 / 19 / 94$ & $21: 11: 43.0$ & 2.5 & 23 & 4.9 & 5.06 & -53 & 29. & 142. & 34.37 & -118.70 & 11. \\
\hline $01 / 21 / 94$ & $18: 39: 15.0$ & 7.5 & 22 & 4.5 & 4.46 & 2. & 54. & 150.6 & 34.30 & -118.46 & 17. \\
\hline $01 / 21 / 94$ & $18: 53: 44.0$ & 2.4 & 22 & 4.2 & 4.27 & -69 & 44. & 70 & 34.32 & -118.48 & 13. \\
\hline $01 / 23 / 94$ & $08: 41: 41.0$ & 3.7 & 21 & 3.6 & 3.8 & -44 & 58 & 98. & 34.29 & -118.46 & 14. \\
\hline $01 / 23 / 94$ & 08:55:09.0 & 5.4 & 21 & 3.8 & 3.98 & -100 & 93. & 1. & 34.30 & -118.32 & 5. \\
\hline $01 / 24 / 94$ & $04: 15: 19.0$ & 2.5 & 22 & 4.2 & 4.49 & -129 & 31. & 1. & 34.28 & -118.57 & 5. \\
\hline $01 / 24 / 94$ & $05: 50: 24.0$ & 2.2 & 22 & 4.2 & 4.23 & 77. & 86. & 38. & 34.36 & -118.63 & 20. \\
\hline $01 / 24 / 94$ & $05: 54: 21.0$ & 1.7 & 22 & 4.1 & 4.12 & 75. & 87. & 29. & 34.37 & -118.63 & 20. \\
\hline $01 / 27 / 94$ & $17: 19: 59.0$ & 3.2 & 22 & 4.3 & 4.46 & -36 & 26. & -66 & 34.27 & -118.56 & 20. \\
\hline $01 / 28 / 94$ & $20: 09: 53.0$ & 3.5 & 22 & 4.3 & 4.05 & -88 & 76. & 82. & 34.37 & -118.48 & 2. \\
\hline $01 / 29 / 94$ & $11: 20: 34.6$ & 6.3 & 23 & 5.1 & 5.1 & 65. & 58. & 1. & 34.38 & -118.67 & 9. \\
\hline $01 / 29 / 94$ & $12: 16: 56.0$ & 1.7 & 22 & 4.1 & 4.19 & -126 & 73. & -3 & 34.28 & -118.61 & 5. \\
\hline $02 / 03 / 94$ & $16: 23: 32.0$ & 1.4 & 22 & 4.0 & 4.2 & -66 & 54. & 90. & 34.33 & -118.41 & 10. \\
\hline $02 / 04 / 94$ & $06: 33: 40.0$ & 4.0 & 21 & 3.7 & 3.50 & -91 & 49. & 30. & 34.28 & -118.62 & 1. \\
\hline $02 / 06 / 94$ & $13: 19: 27.0$ & 7.7 & 21 & 3.9 & 4.07 & -27 & 30. & 128. & 34.28 & -118.49 & 11. \\
\hline $02 / 06 / 94$ & $13: 21: 45.0$ & 5.1 & 21 & 3.8 & 3.7 & -32 & 40. & 123. & 34.35 & -118.50 & 9. \\
\hline $02 / 11 / 94$ & 14:07:53.0 & 3.0 & 21 & 3.6 & 3.56 & -47 & 61. & 101. & 34.34 & -118.48 & 9. \\
\hline $02 / 18 / 94$ & $09: 13: 28.0$ & 4.4 & 21 & 3.7 & 3.64 & 138 & 42. & 69. & 34.24 & -118.57 & 13. \\
\hline $02 / 25 / 94$ & $12: 59: 13.0$ & 7.3 & 21 & 3.8 & 3.97 & -102 & 63. & 62. & 34.36 & -118.38 & 5. \\
\hline $03 / 10 / 94$ & $12: 44: 15.0$ & 1.2 & 21 & 3.3 & 3.53 & 50. & 53. & 349. & 34.23 & -118.47 & 5. \\
\hline $03 / 20 / 94$ & $21: 20: 10.0$ & 1.2 & 24 & 5.3 & 5.35 & -52 & 40. & 106. & 34.28 & -118.42 & 14. \\
\hline $04 / 06 / 94$ & 19:01:04.0 & 5.5 & 22 & 4.4 & 4.83 & 23. & 67. & 7. & 34.19 & -117.10 & 10. \\
\hline $04 / 07 / 94$ & $04: 19: 29.0$ & 2.8 & 21 & 3.6 & 3.47 & -104 & 74. & 48. & 34.34 & -118.46 & 9. \\
\hline $04 / 27 / 94$ & $12: 33: 10.0$ & 7.5 & 21 & 3.9 & 3.49 & -43 & 35. & 98. & 34.26 & -118.74 & 14. \\
\hline $05 / 04 / 94$ & $04: 09: 13.0$ & 1.3 & 21 & 3.3 & 3.64 & -104 & 89. & 30. & 34.33 & -118.45 & 6. \\
\hline $05 / 16 / 94$ & $08: 40: 47.0$ & 2.9 & 21 & 3.6 & 3.73 & -73 & 35. & 95. & 34.31 & -118.62 & 25. \\
\hline $05 / 25 / 94$ & $12: 56: 57.0$ & 4.6 & 22 & 4.4 & 4.18 & -81 & 31. & 78. & 34.31 & -118.39 & 9. \\
\hline $05 / 28 / 94$ & $17: 15: 12.0$ & 4.3 & 21 & 3.7 & 3.60 & 71. & 74. & 40. & 34.35 & -118.68 & 20. \\
\hline $06 / 02 / 94$ & $03: 27: 14.0$ & 4.4 & 21 & 3.7 & 3.69 & 118. & 50. & 48. & 34.27 & -118.40 & 13. \\
\hline $06 / 15 / 94$ & $05: 59: 49.0$ & 8.7 & 21 & 3.9 & 3.99 & 141. & 43. & 83. & 34.31 & -118.40 & 11. \\
\hline $07 / 11 / 94$ & $06: 50: 50.0$ & 5.8 & 21 & 3.8 & 3.72 & -101 & 56. & 63. & 34.26 & -118.69 & 18. \\
\hline $08 / 19 / 94$ & $06: 56: 10.0$ & 3.4 & 21 & 3.6 & & -54 & 30. & 92. & 34.26 & -118.75 & 15. \\
\hline
\end{tabular}




\section{Dip-slip earthquakes}

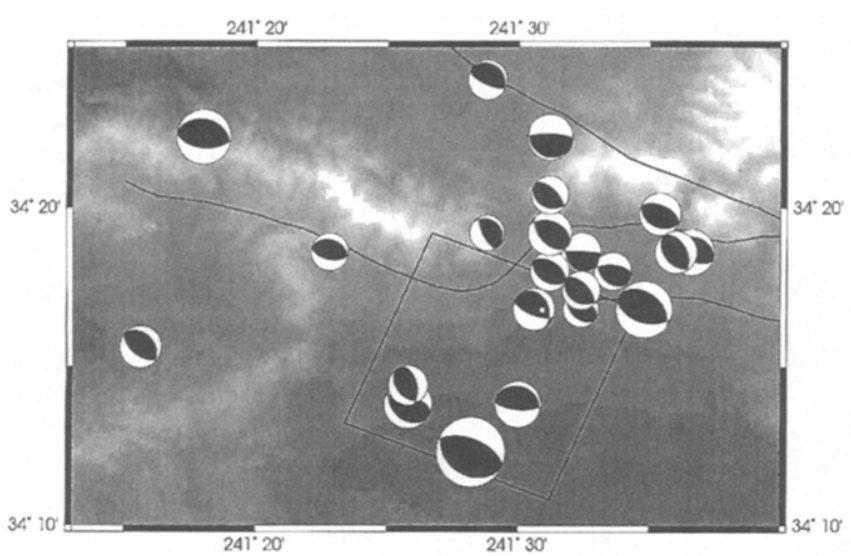

Strike-slip earthquakes

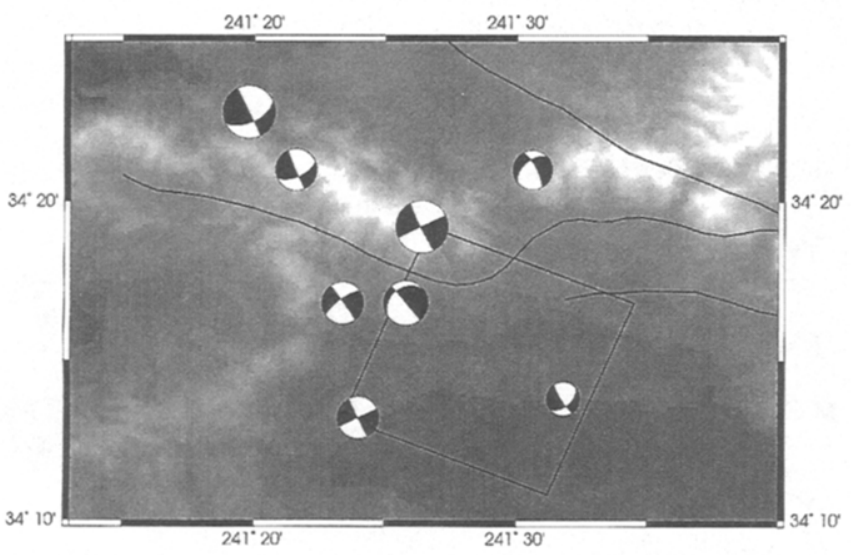

Oblique earthquakes

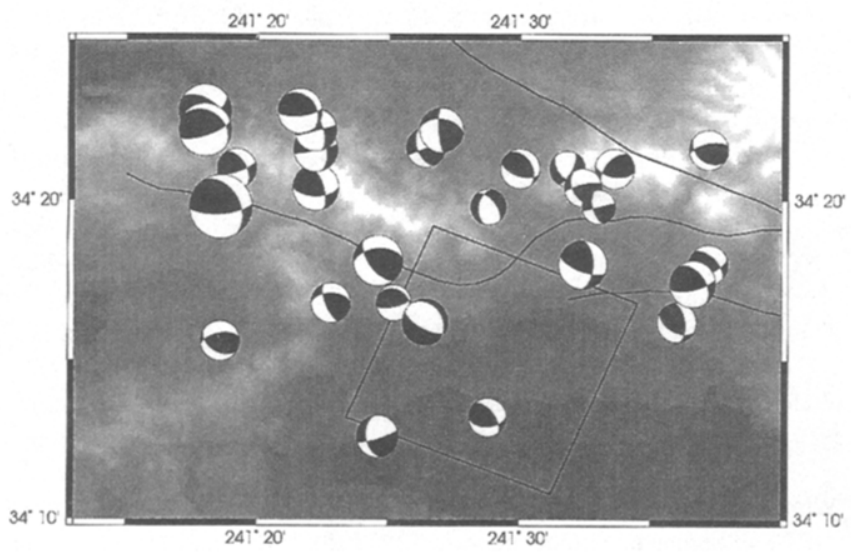

Figure 8. Topographic map of the Northridge area showing the mechanisms determined using short-period surface waves. (a) Thrust mechanisms; the large event at the bottom center is the mainshock. (b) Strike-slip mechanisms. (c) Oblique mechanisms. the locations in the aftershock region, which might indicate differences in stress drop. However, as can be judged from Figure 9, there is no evidence for that from these ratios alone.

\section{Discussion}

Our results for the mainshock rupture are consistent with the results obtained by Wald and Heaton (1994) and Dreger (1994), which favor slip occurring at large depths. They are not consistent with the results by Hudnut $e t$ al. (1994), who find shallower depths. These differences may be caused by differences in crustal models. Our teleseismic inversion results as well as the results of Wald and Heaton (1994) show no evidence of mechanism changes during rupture, suggesting that the rupture plane is simple in geometry. This finding is in contrast to the San Fernando earthquake for which Langston (1978) and Heaton (1982) found evidence for a change in dip angle. Further evidence for simplicity of the rupture plane comes from the observation that the aftershocks in the rupture area are very similar in mechanism to the mainshock.

Outside the immediate rupture plane, however, the fault geometry seems to become more complicated. Mori et al. (1994) concluded that the upper continuation of the rupture plane is cut off by the rupture plane of the San Fernando earthquake, which broke to the surface. To the west, our aftershock mechanisms suggest that the fault geometry changes, ultimately resulting in a zone of more east-west-

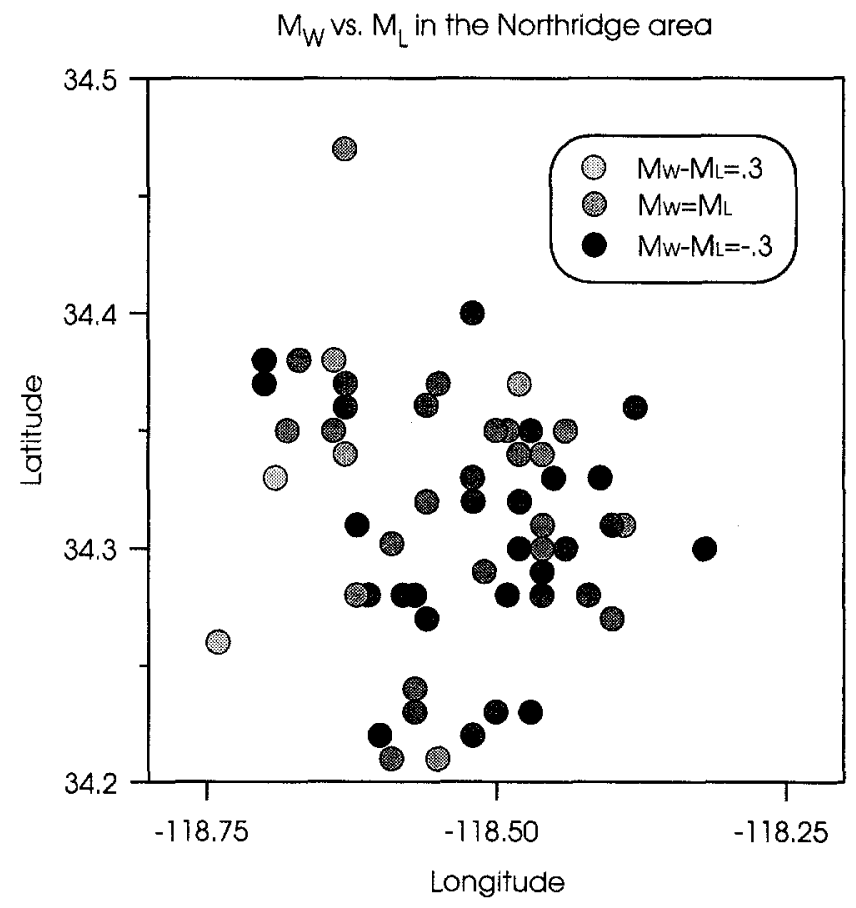

Figure 9. $M_{L} / M_{W}$ ratios for the Northridge aftershock sequence. Dark colors are low ratios $\left(M_{L}>\right.$ $\left.M_{W}\right)$, and light colors are high ratios $\left(M_{L}<M_{W}\right)$. 
striking fault planes separated from the mainshock area by a zone with more strike-slip or oblique mechanisms.

We suggest that this change in mechanism is a manifestation of structural complexity that limited the extension of the Northridge rupture. Thio and Kanamori (1995b) observed for several large strike-slip earthquakes that complexity of the structure has a significant influence on the rupture process itself, causing complex rupture time histories or mechanism changes. This effect may also explain the high stress drop of this earthquake. The stress drop, 270 bars, of the Northridge earthquake is high, but as discussed previously, high stress drop is commonly found for earthquakes in the Transverse Ranges and also was found during the 1992 Landers earthquake (Kanamori, 1994). High-stressdrop earthquakes are usually associated with relatively long recurrence times of earthquakes, as suggested by Kanamori and Allen (1986) and Scholz et al. (1986). One possible mechanism is that the faults in the Transverse Ranges with low slip rates have not developed to a single through-going fault. Faults do not evolve as a single propagating crack but rather as a system of smaller cracks that progressively grow into a single fault (Scholz, 1989). An example of this growth is the development of en-echelon faults that are observed in the early stages of strike-slip faults (e.g., Mandl, 1988). Discontinuities in faulting may inhibit propagation of a rupture front, thereby limiting the extent of the rupture zone. This mechanism, combined with a slip pulse (Heaton, 1990), causes high-stress-drop events. In the slip-pulse model (Heaton, 1990), the slip during rupture occurs in a narrow band and propagates on a fault plane. In general, slip pulses with large displacements tend to propagate over a large distance, which gives rise to the relationship between slip and fault length. However, if the slip is stopped by irregularities of fault geometry, the ratio of slip to rupture becomes large, resulting in a high-stress-drop event.

\section{Acknowledgments}

We would like to thank Holly Given and Pete Davis for their help in obtaining IRIS/IDA data. This research was supported by the USGS Grant Number 1434-93-G-2287 and NSF Grant Number EAR-9416120. Division of Geological and Planetary Sciences Contribution No. 5580.

\section{References}

Bent, A. L. and D. V. Helmberger (1989). Source complexity of the October 1, 1987, Whittier Narrows earthquake. J. Geoph. Res. 94, B7, 95489556.

Dreger, D. S. (1994). Empirical Green's function study of the January 17, 1994 Northridge mainshock $\left(M_{\mathrm{w}}\right.$ 6.7). Geoph. Res. Lett. 21, 26332636.

Dreger, D. S. and D. V. Helmberger (1991a). Complex faulting deduced from broadband modeling of the 28 February 1990 Upland earthquake $\left(\mathbf{M}_{\mathrm{L}}=\right.$ 5.2). Bull. Seism. Soc. Am. 81, no. 4, 1129-1144.

Dreger, D. S. and D. V. Helmberger (1991b). Source parameters of the Sierra Madre earthquake from regional and local body waves. Geophys, Res. Lett. 18, no. 11, 2015-2018.
Hauksson, E., L. M. Jones, and K. Hutton (1995). The 1994 Northridge earthquake sequence in California: seismological and tectonic aspects, J. Geophys. Res. 100 B7, 12335-12355.

Heaton, T. H. (1982). The 1971 San Fernando earthquake: a double event? Bull. Seism. Soc. Am. 72, no. 6, 2037-2062.

Heaton, T. H. (1990). Evidence for and implications of self-healing pulses of slip in earthquake rupture. Phys. Earth Planet Interiors 64, 1-20.

Hudnut, K. W., M. H. Murray, Z. Donnellan, Y. Bock, P. Fang, Y. Feng, Z. Shen, B. Hager, T. Herring, and R. King (1994). Co-seismic displacements of the 1994 Northridge, California, earthquake. AGU fall meeting abstract, EOS, Nov. 1, p. 176.

Kanamori, H. (1994). Mechanics of earthquakes, Ann. Rev. Earth Planet. Sci. 22, 207-237.

Kanamori, H. and C. A. Allen (1986). Earthquake repeat time and average stress drop, in Earthquake Source Mechanics, American Geophysical Monograph 37, 227-235.

Kanamori, H., J. Mori, and T. H. Heaton (1990). The 3 December 1988, Pasadena earthquake $\left(M_{L}=4.9\right)$ recorded with the very broadband system in Pasadena. Bull. Seism. Soc. Am. 80, no. 2, 483-487.

Kanamori, H., J. Mori, E. Hauksson, T. H. Heaton, L. K. Hutton, and L. $M$. Jones (1993). Determination of earthquake energy release and $M_{L}$ using TERRAscope. Bull. Seism. Soc. Am. 83, no. 2, 330-346.

Kikuchi, M. and H. Kanamori (1991). Inversion of complex body wavesIII, Bull. Seism. Soc. Am. 81, no. 6, 2335-2350.

Langston, C. A. (1978). The February 9, 1971 San Fernando earthquake: a study of source finiteness in teleseismic body waves. Bull. Seism. Soc. Am. 68, no. 1, 1-29.

Mandl, G. (1988). Mechanics of Tectonic Faulting: Models and Basic Concepts, Elseviur Science Pub., Amsterdam, 407 pp.

Magistrale, H., H. Kanamori, and C. Jones (1991). Forward and inverse 3dimensional P-wave velocity models of the Southern California crust. J. Geophys. Res. 97, B10, 14115-14135.

Mendoza, C. and S. H. Hartzell (1988). Aftershock patterns and mainshock faulting. Bull. Seism. Soc. Am. 78, no. 4, 1438-1449.

Mori, J., D. Wald, and R. Wesson (1994). Overlapping fault planes of the 1971 San Fernando and 1994 Northridge, California, earthquakes, Geoph. Res. Lett. 22, no. 9, 1033-1036.

Norris, R. M. and R. W. Webb (1990). Geology of California, Wiley and Sons, New York, 541 pp.

Scholz, C. H. (1989). Mechanics of faulting. Ann. Rev. Earth Planet. Sci. 17, 309-334.

Scholz, C. H., C. A. Aviles, and S. G. Wesnousky (1986). Scaling differences between large and intraplate earthquakes, Bull. Seism. Soc. Am. $76,65-71$.

Scientists of the USGS and Southern California Earthquake Center (1994). The Magnitude 6.7 Northridge, California, earthquake of January 17, 1994, Science 266, 389-397.

Thio, H. K. and H. Kanamori (1995a). Moment tensor inversions for local earthquakes using surface waves recorded at TERRAscope. Bull. Seism. Soc. Am., in press.

Thio, H. K. and H. Kanamori (1995b). Source processes of large on-land strike-slip earthquakes, in press.

Wald, D. J. and T. H. Heaton (1994). A dislocation model of the 1994 Northridge, California, earthquake determined from strong ground motions. U.S. Geol. Surv. Open-File Rept. 94-278.

Whitcomb, J. H., C. R. Allen, J. D. Garmany, and J. A. Hileman (1973). San Fernando earthquake series, 1971: focal mechanisms and tectonics. Rev. Geophys. Sp. Ph., 11, no. 3, 693-730.

Seismological Laboratory

California Institute of Technology

Pasadena, California 91125

Manuscript received 19 January 1995. 